\title{
Destinos, Escolhas e a Democratização do Ensino Superior
}

Maria Ligia de Oliveira Barbosa'

\section{Resumo}

Este artigo analisa algumas das diversas políticas (tanto governamentais quanto institucionais) que visam a assegurar o acesso e a permanência dos estudantes até a conclusão dos cursos no sistema brasileiro de ensino superior. Trata-se de uma tentativa de avançar na discussão sobre qual seria uma democratização possível para esse sistema. O artigo busca verificar se, apesar da manutenção dos padrões de desigualdade estrutural, de prestígio e renda, seria possível encontrar políticas que se contraponham a essa tendência. Foram analisadas as políticas de cotas raciais e sociais, o Reuni e o ProUni, bem como o programa de interiorização da Universidade Federal Fluminense (UFF) e de estágios e bolsas na Pontifícia Universidade Católica de Minas Gerais (PUC-Minas). Foram utilizadas pesquisas feitas por pesquisadores do LAPES/UFRJ/CNPq. O material analisado permite confirmar a existência de ações e políticas que criam probabilidades efetivas de que Escolhas dos indivíduos e grupos possam prevalecer sobre os Destinos socialmente desenhados para eles.

Palavras-chave: Ensino Superior. Democratização. Políticas sociais. Acesso ao ensino superior. Permanência no ensino superior.

\section{Introdução}

Nos últimos tempos, o tema do ensino superior saiu de sua discrição usual e ganhou destaque, aparecendo, inclusive, como capa de uma revista internacional de enorme circulação ${ }^{2}$, sendo objeto de inúmeras reportagens em jornais brasileiros de grande circulação, possivelmente o nível terciário de ensino tenha, finalmente, entrado na agenda pública. Para as famílias, e não

1 Professora associada da Universidade Federal do Rio de Janeiro, onde coordena o LAPES (Laboratório de Pesquisa em Ensino Superior/UFRJ/CNPq).Tem experiência na área de Sociologia, com ênfase em Sociologia da Educação, atuando principalmente nos nostemas: desigualdades sociais, ensino superior e profissões. É Vice-Presidente para América Latina do RC04 - Sociology of Education - da ISA (International Sociological Association) 2010-2014 e 2014-20/8. http://lattes.cnpq.br/54364827/3562659

2 The Economist, em 28 de março de 2015. (http://www.economist.com/printedition/2015-03-28) Nessa edição, a revista britânica faz uma longa reportagem especial sobre as universidades no mudo de hoje. Começando pela debate que opõe Excelência versus Equidade, passando pela instalação da New York University em Abu Dhabi, a reportagem também mostra a desvalorização do ensino superior tecnológico, em todo mundo considerado como "pouco classudo", responsável pela desvalorização social desse segmento de formação. 
apenas aquelas da classe média tradicional, a possível entrada de seus filhos na universidade tornou-se assunto de interesse. Para os analistas dos mais diversos matizes, o funcionamento adequado das instituiçóes de ensino superior tem se tornado um elemento central na afirmação dos princípios democráticos e da igualdade de oportunidades nas sociedades modernas, como indicou o então editor da revista internacional, John Micklethwait. A entrada do tema na agenda pública pode ser um indicativo de que talvez Backer (2014) tenha alguma razão na sua visão do sistema de ensino, principalmente superior, seja o núcleo propulsor de uma revolução que alterou profundamente as sociedades ocidentais nos últimos 150 anos. De sua perspectiva, mais que um fator associado à modernizaçáo da sociedade, a Educação Escolar - particularmente nas instituiçóes de ensino superior - seria a principal e grande matriz da organização da vida social. Não apenas uma das revoluçóes que conjuntamente produziram a modernidade (segundo Raymond Williams: industrial, urbana, cultural, educacional), mas $A$ Revoluçâo que, nos últimos 150 anos, redesenhou os critérios de hierarquização social, os padrôes de produção científica, as práticas médicas, as formas de organização familiar, o tecido urbano (BACKER, 2014). Enfim, a revolução que teria redesenhado o mundo social. Mesmo se há exagero, o tema é incontornável atualmente: o sistema de ensino superior tornou-se, mais que o "Destino" de uns poucos privilegiados, uma escolha possível para muitos cidadãos.

No espaço do Laboratório de Pesquisa sobre Ensino Superior LAPES/ UFRJ/CNPq têm sido discutidas aquelas que parecem ser as questóes centrais colocadas pela expansáo recente do sistema de ensino superior brasileiro. Examinando a entrada significativa de estudantes de origens sociais mais populares ou a permanência do viés acadêmico, os trabalhos do LAPES buscam analisar as condiçóes sociais para uma possível democratizaçáo do ensino superior brasileiro. Nesse quadro, este artigo analisa algumas das diversas políticas (tanto governamentais quanto institucionais) visando a assegurar a permanência dos estudantes até a conclusão dos cursos. Na verdade, este estudo é uma tentativa de avançar na seguinte discussáo proposta por François Dubet (2015): qual a democratização possível para o nosso $\mathrm{SES}^{3}$ ? Se há indícios de que a fortíssima expansão não reduziu padróes de desigualdade estrutural (medidas de prestígio

3 Sistema de Ensino Superior (SES) 
e renda), como mostram Ribeiro, Ceneviva e Brito et al. (2015), seria possível encontrar políticas que se contraponham a essas tendências?

\section{Uma estrutura durável de desigualdade social}

Quando se inaugurou o período histórico que podemos classificar como moderno, a sociedade revolucionada estabeleceu novos princípios de organização, diferenciação e hierarquizaçáo. Teoricamente, nessa nova sociedade, o talento, o esforço, o desempenho eram qualidades mais importantes que o nome do pai ou do avô na hora de buscar trabalho. Aliás, procurar trabalho deixou de ser castigo ou vergonha para se tornar uma forma de realizaçáo pessoal. Estas seriam mudanças nada triviais, como atestam o próprio surgimento de uma ciência do social e obras clássicas nessa área, justamente porque a instalação desses novos princípios de organização social se mostrou mais complexa, a educação escolar tornou-se objeto de pesquisa social e de atenção pública.

Quanto mais abrangente se torna o público atingido por um determinado segmento do sistema escolar, mais intensas serão as luzes do debate sobre o sentido e os modos de funcionamento da escolarização na sociedade. $\mathrm{O}$ foco atual, em todas as sociedades nacionais, é o sistema de ensino superior. Em uma expansão espetacular - no ano 2000, existiam no mundo mais de 100 milhóes de estudantes universitários (SCHOFER; MEYER, 2005) - o SES, em cada país, surge como um dos pilares da democratização das sociedades modernas.

Se os processos históricos e sociais envolvidos no desenvolvimento do SES são bastante diversos, a pergunta comum indaga sobre a capacidade que esse sistema teria de oferecer um efetivo aumento da igualdade de oportunidades sociais. Em outras palavras, nos termos da pergunta clássica das teorias da estratificação social: em que medida o SES consegue suplantar o peso da origem social na definição dos Destinos Ocupacionais dos indivíduos?

Infelizmente, a tendência das respostas tende a ser negativa. Fatores estruturais indicam uma importante tendência ao fortalecimento da desigualdade no mesmo quadro de expansão significativa da matrícula nesse nível de ensino. Isso acontece nos mais diferentes países. O instigante estudo de Goldthorpe e Jackson (2008) mostra como a expansão educacional na Inglaterra não conduziu a uma afirmação da meritocracia. Ao contrário, em uma 
conclusão terrivelmente pessimista, os autores indicam que as barreiras para o desenvolvimento de uma sociedade baseada em princípios meritocráticos são muito fortes. Associando três variáveis essenciais nessa análise, origem social, habilidades acadêmicas e realização educacional, os autores mostram que a origem social permanece sendo um fator essencial na definiçáo do nível ocupacional atingido pelos indivíduos. $\mathrm{Na}$ sociedade britânica!

Para o caso brasileiro, Ribeiro, Ceneviva e Brito et al. (2015) mostram como as barreiras às transiçóes educacionais vão se elevando ao longo do sistema de ensino. Se essas barreiras ou dificuldades foram anuladas no ensino fundamental em função de sua virtual universalização, no ensino médio e, mais ainda, no ensino superior, encontram-se ainda importantes obstáculos sociais à conclusão exitosa de cada um dos níveis. Segundo os autores, haveria uma clara associação positiva entre a renda domiciliar e as chances de conclusão do ensino superior. Também, quanto maior a escolaridade materna, maiores são as probabilidades de conclusão do ensino superior.

A origem social tem sido, entáo, um fator importantíssimo no desempenho escolar, na realização educacional e tem impactos inclusive sobre o quanto a educação pode (ou náo) pesar na definição do Destino Ocupacional.

Inúmeras são as explicaçóes possíveis para esse fenômeno. A partir das teorias da estratificação desenvolve-se tanto a hipótese MMI (Desigualdade Maximamente Mantida, traduzindo a sigla em inglês) como a EMI (traduzindo: Desigualdade Efetivamente Mantida). Como mostra Boliver (2010, p. 3), essas duas hipóteses explicativas indicam que a "[...] quantidade e a qualidade da educação obtida por membros de diferentes grupos socioeconômicos não tenderiam a melhorar pela simples expansão das oportunidades educacionais". Um argumento metodológico importante deve ser ponderado: a expansão do sistema educacional é medida pelo aumento dos anos de escolaridade dos indivíduos em uma dada população. Essa é uma medida da quantidade de escolarizaçáa, que considera pouco as diferenças quanto à qualidade desta, com a exceção possível da EMI. Essas diferenças qualitativas (tanto quanto à excelência das instituiçóes de ensino como em relação aos distintos tipos de conhecimento associados a cada formação) podem, pelo menos hipoteticamente, estar sendo capturadas como efeitos da origem social e náo do processo educacional. Se essa hipótese se confirma, há muita pesquisa a ser feita, 
especialmente considerando os efeitos dos novos padróes de excelência e da divisão técnica do trabalho nos níveis mais elevados do sistema educativo.

Essas explicaçóes geraram e geram ainda um debate imenso sobre as tendências das sociedades modernas com pretensóes meritocráticas. Na verdade, busca-se entender por que a desigualdade permanece mesmo em casos de expansão do sistema educacional, um recurso essencial nessas novas sociedades.

Fatores como os efeitos perversos de Boudon (em que a ação racional individual pode produzir irracionalidade coletiva) ou a independência relativa do sistema de educaçáo e do mercado de trabalho, como quer Bourdieu, abrem interessantes caminhos de análise. As estratégias da elite, alongando os percursos escolares ou "qualificando" distintamente os anos de escolaridade segundo a instituição, são indicadas em estudos de Goldthorpe. A competição institucional para atingir qualidade internacional reorganiza o sistema universitário, como mostra Carlos Benedito Martins, e tende a diferenciar essas instituiçôes. $\mathrm{O}$ viés acadêmico e a distinção entre universidades vocacionais e de pesquisa podem se traduzir em desigualdades importantes no mercado de trabalho, como indicam Simon Schwartzman ou Antônio Augusto Prates.

Em todos esses casos, há indicaçóes de que a manutenção, o reforço ou a diminuição dessas estruturas duráveis de desigualdade passa por valores, práticas institucionais, açôes coletivas (TILLY, 1998). Reafirma-se a perspectiva weberiana de que as constelaçóes de poder social são contingentes, dependentes das práticas sociais dos agentes ou atores envolvidos.

Sendo assim, Dubet (2015) indica que uma possível democratizaçáo do SES depende de uma série de variáveis relativas ao funcionamento desse sistema. Ou seja, é preciso examinar mais de perto o que vem acontecendo no SES para avaliar em que grau ele contribui ou náo para esse acirramento das desigualdades sociais que parece estar associado à expansão das matrículas. É como se tentássemos retomar o argumento de Jencks (1972) contra a perspectiva acachapante do relatório Coleman, que atribuía todas as diferenças de desempenho entre os alunos aos impactos da sua origem social distinta. Não haveria possibilidades de que as instituiçóes pudessem ter algum efeito democratizante ou que, pela sua qualidade, pudessem garantir que todo e qualquer estudante aprendesse bem, independentemente de sua posiçáo social, raça ou sexo. A pesquisa de Jencks começou como um contraponto impressionista 
a uma das conclusóes mais centrais do relatório Coleman: a escola não faria nenhuma diferença. Jencks mostra que, como qualquer cidadão pode notar, passar pela escola faz, sim, muita diferença. Nosso argumento inicial é menos impressionista, mas muito relacionado aos valores e às percepçóes: para os jovens que ingressam no ensino superior, sendo os primeiros de suas famílias a chegar a esse nível de escolaridade, "estar na universidade" significa um passo muito importante (CARRANO, 2009).

Outra dimensão do argumento de Jencks (1972) trata da técnica estatística utilizada por Coleman. Sem contar ainda, naquela época, com os métodos de análise multinível, o trabalho de Coleman e seus colaboradores não teve condiçóes de considerar adequadamente os efeitos do contexto escolar, seja a instituição como um todo, sejam os colegas ou pares, sejam os professores ${ }^{4}$. Neste caso, Jencks (1972) chama a atenção para os possíveis efeitos institucionais sobre as trajetórias individuais. Estas não seriam apenas influenciadas pela origem familiar do estudante, visto que também sofreriam impactos importantes da instituição escolar.

Se as desigualdades de utilidade ou o valor social das diferentes formaçóes e diplomas acabam por ter impacto significativo sobre o conjunto das desigualdades sociais (MARTINS e MACHADO, 2015), elas podem ser contrapostas por açóes e políticas de aumento e equalização das oportunidades educacionais (DUBET, 2015). Geralmente, elas visariam a aumentar as chances de permanência de todos os estudantes e, assim, as diversas instituições dos sistemas educativos criariam distintos procedimentos de seleção, de concessáo de gratuidades, bolsas, auxílios, os quais podem ser considerados como mais ou menos equitativos segundo as normas de justiça que mobilizam. Por outro lado, essas açóes podem ser mais ou menos eficazes como promotoras de maior igualdade de oportunidades.

Trata-se de discutir, na verdade, a efetividade ou o poder de agência que governos e instituiçóes poderiam ter no combate às desigualdades estruturais e duráveis ou, nos termos weberianos, trata-se de verificar em que medida as "Escolhas" individuais e/ou institucionais podem se contrapor ao Destino ocialmente esenhado pelas estruturas de desigualdade.

4 A esse respeito ver especialmente o capítulo 5 de Forquin, 1995. 


\section{Programas e Políticas: agência institucional para maior igualdade de oportunidades}

Para examinar essa perspectiva de agência institucional, utilizaremos alguns dos trabalhos realizados por pesquisadores do LAPES e por colegas de outras instituiçóes nos últimos anos. Serão enfocadas políticas públicas (quotas raciais e sociais; ProUni e Reuni) ou açóes institucionais (como o programa de interiorização da UFF e o programa de estágios da PUC-Minas). Também seria importante avaliar debates e resistências à implantação dessas políticas e açôes. Entretanto, no espaço de um artigo, elas poderão apenas ser mencionadas sem uma discussão mais aprofundada.

\section{I Políticas Públicas de Acesso: cotas raciais e sociais}

O debate sobre as políticas de cotas raciais e sociais não pode ser resumido em algumas poucas linhas. Tema que atravessa a clássica separação entre "direita" e "esquerda", talvez tenha sido o maior divisor de águas no mundo acadêmico brasileiro (MOEHLECKE, 2002; SCHWARTZMAN, 2006). Ainda assim, em proporçôes e formatos variados, foram estabelecidas diversas políticas de ação afirmativa, fortemente enfatizadas pelo governo federal.

Como mostram Neves e Anhaia (2014, p. 381):

A forma descentralizada em que as ações afirmativas foram implementadas no Brasil possibilitou uma grande variedade de experiências [...]. Hoje existem diferentes modelos de políticas afirmativas: cotas raciais, cotas sociais para alunos oriundos de escolas públicas e o modelo de acréscimo de bônus. Até 2010, 88 IES públicas haviam implantado ações afirmativas em seus processos seletivos. Com relação às IES federais, constatava-se que 28 universidades já possuíam políticas afirmativas em seus processos seletivos, das quais, 24 adotaram o sistema de cotas e 4 adotaram o sistema de acréscimo de bônus. No caso das cotas sociais e raciais, havia reserva de 10 a $50 \%$ das vagas a todos que frequentaram o ensino médio em escola pública e que se autodeclararam pretos/pardos ou indígenas.

Como a pesquisa indica, houve uma efetiva ampliação do acesso ao ensino superior e os jovens beneficiários dessas políticas demonstram ter uma avaliação positiva do processo (NEVES; ANHAIA, 2014). Quando se considera o acesso ao ensino superior, inegavelmente houve uma abertura acentuada permitindo a entrada de estudantes provenientes de setores anteriormente excluídos desse nível de escolarização. Por exemplo, segundo Heringer e Honorato 
(2014, p. 317), o número “[...] de estudantes matriculados em instituiçóes federais de ensino dobrou de 2003 a 2011; e, o de negros, quadruplicou entre 1997 e 2011”. Entretanto, como já destacaram essas autoras mencionadas, o acesso não garante o sucesso da trajetória escolar, fato sobejamente conhecido nos estudos da sociologia da educaçáo (FORQUIN, 1995).

Trata-se do ponto-chave desta análise: em que medida esse acesso mais ampliado pode ser visto como um fortalecimento da igualdade de oportunidades educacionais?

As dificuldades de acesso encontradas por jovens pobres e negros podem ser associadas ao funcionamento geral do sistema de ensino brasileiro, extremamente desigual em termos da qualidade oferecida aos alunos provenientes de distintos grupos sociais. Entretanto, quando esses jovens conseguem realizar essa transição decisiva - finalização do ensino médio e entrada no nível terciário -, sua vitória nem sempre se traduz em sucesso escolar; isso ocorre, talvez, porque o Destino socialmente atribuído a eles teime em anular as Escolhas feitas, tanto por eles mesmos quanto por açóes políticas.

Depoimentos colhidos por Neves e Anhaia (2014, p. 381) permitem avaliar que a entrada no mundo novo da universidade tem impactos importantes na vida desses jovens. Mais que efeitos econômicos, eles indicam que houve uma abertura para o mundo do conhecimento, antes náo imaginado por eles. A experiência da vida universitária pode produzir mudanças no cotidiano desses jovens, alterando muitas vezes os roteiros previstos. Junto disso vem, também, um orgulho por estarem em uma posição mais elevada, pelo fato de terem chegado onde ninguém na família anteriormente teria conseguido. Por outro lado, conforme indicação de pesquisas coletadas por Carrano (2009, p. 189), o ingresso na universidade é valorizado por alguns jovens porque essa entrada daria a eles a possibilidade de desenvolverem uma "cultura" que valoriza a educação. Sua escolarização superior faria com que suas famílias aprendessem a dar maior valor à escola.

Todos esses aspectos são bastante positivos. No entanto, associados a eles existem algumas percepçóes bem menos positivas. Como já mostravam os trabalhos de Almeida (2007, 2009), o ambiente universitário é visto como uma mistura de felicidade e estranhamento: o espaço institucional pode ser difícil, estranho e até mesmo hostil. As dificuldades encontradas para se informar 
sobre a vida universitária vão desde a falta de indicaçóes e informaçóes claras sobre a localizaçáo física dos prédios - com nossos campi sendo desenhados para serem lidos e vividos por aqueles que "naturalmente" aprenderam a lógica dos locais - até a ausência de conhecimento das regras do jogo burocrático (como ter acesso ao alojamento estudantil ou às bolsas para cotistas) ou acadêmico (como fazer trabalhos aceitáveis para os professores, como dialogar com os colegas, como se comportar nos ambientes coletivos).

Outro tipo de dificuldade estaria associado à precariedade da formação básica de muitos desses jovens provenientes das camadas ditas populares (CARRANO, 2009, p. 193). A isso, também se alia um desconhecimento razoavelmente amplo sobre a natureza do trabalho realizado em cada carreira profissional. Esses são dois fatores importantes de evasão, especialmente nos primeiros anos dos cursos superiores. Começando pela formaçáo no ensino básico, sabidamente de baixa qualidade média no Brasil, apesar da existência de instituiçóes excelentes - jamais reservadas para as classes populares. Tomando apenas um exemplo mais gritante que seria o ensino de matemática. Disciplina que os docentes, em sua maioria, desconhecem não só o conteúdo como também as especificidades didáticas a ela associadas, a matemática aparece como o grande vilão ou a grande dificuldade a ser superada por indivíduos que querem entrar na universidade. E, para muitos dos que conseguem entrar, a barreira tem um nome: Cálculo 1, disciplina campeá de reprovação no ensino superior, problema sério na área de Ciência, Tecnologia, Engenharias e Matemática $\left(\mathrm{CTEM}^{5}\right)$. O funcionamento dessa disciplina como barreira pode ser observado na dissertação de Bastos (2004), na qual há comparação entre alguns estudantes de Ciências Sociais e de Física, entre outros, da UFRJ. A entrada para o curso de Física é muito semelhante, em termos de perfis sociais, daquela das ciências sociais. No entanto, quando se chega à pós-graduaçáo, a física se torna mais masculina, branca e afluente. Explicação corrente entre os próprios alunos: os estudantes que não conseguem passar na disciplina Cálculo 1 deixam o bacharelado e dirigem-se à licenciatura, visto que nesta a

5 Ver, a esse respeito, a coletânea de artigos produzida pela Rede de Pesquisa Formação e Mercado de Trabalho, volume IV, Formação de profissionais das áreas de Ciência, Tecnologia. Engenharia e Matemática (CTEM), organizado por Oliveira et al em 2014. Disponivel em: http://www.abdi.com.br/Estudo//41027_abdi_ipea_ vol4.pdf. Para esse tema em particular, ver Barbosa e Zuccarelli, 2014. 
referida matéria não era considerada relevante ${ }^{6}$. Fica evidente, nesse tipo de observação, que um determinado conteúdo disciplinar ou, mais que isso, a forma ou o método didático utilizado para ensiná-lo, tem efeitos socialmente distintos sobre os estudantes. Obviamente, isso é um tema importantíssimo na sociologia do currículo e vem sendo trabalhado no Brasil (GRIPP, 2014; MAINARDES; GANDIN, 2013). Isso é importante de ser notado pois não se trata de um problema biológico, de incompetência intelectual para "dar conta" de certos tipos de conhecimento. Estamos diante de uma incompetência social na transmissão desses conhecimentos. Incompetência essa que atinge particularmente as crianças e os jovens desprivilegiados de nosso país, e, aparentemente, é a base de uma barreira - ou pelo menos uma dificuldade relevante - para a permanência de jovens pobres no ensino superior.

Outra dimensão associada às diferenças disciplinares seria o pouco conhecimento, o qual muitas vezes prevalece mesmo entre jovens dos grupos de elite, sobre o efetivo conteúdo das áreas de conhecimento que são oferecidas nas universidades ou nos centros tecnológicos, por exemplo. Se são conhecidos os casos de desistência do Curso de Medicina - supostamente um trabalho muito bem conhecido - depois da primeira aula de anatomia, em outras áreas o fenômeno se repete com diferentes nuances. Até mesmo na escolha de estudantes que entraram para as ciências sociais julgando que assim poderiam escapar da matemática e da estatística. Esse tema também se torna relevante, como mostra Caruso (2014), pois tem pelo menos duas dimensões. Um lado do mercado, que tem necessidades de competências técnicas em determinadas áreas e uma dimensáo de fazer o ajuste entre as habilidades ou aptidóes individuais e as carreiras profissionais. Sem dúvida, isso abre toda uma série de questôes de pesquisa na sociologia das profissóes. Ressalte-se, entretanto, que o poder de agência institucional e de construçáo das regras sociais, detido pelos grupos profissionais, molda fortemente as tendências de organização dos sistemas de ensino superior. Tanto nas suas formas de funcionar, nos seus mecanismos burocrático-institucionais, quanto nos conteúdos disciplinares (BARBOSA, 2015). Algumas evidências sutis dessas diferenças entre os grupos profissionais quanto à forma de lidar com o sistema de ensino superior

6 Aparentemente, a aprovação em Cálculo I passou a ser exigida nas licenciaturas. Será uma medida importante se for efetivamente aplicada. 
aparecem em Barbosa e Santos (2011), mesmo que muito matizado pelo tipo de dado utilizado na análise. Nesse caso, aparecem diferenças significativas entre cursos das três grandes áreas consideradas, biológicas, exatas e humanas, no que diz respeito à sua maior ou menor permeabilidade social de algumas carreiras: as proporçóes de alunos financiados e o tipo de financiamento variam bastante. Dentro de cada carreira analisada, pode-se notar diferenças de desempenho associadas aos tipos distintos de financiamento para a permanência no curso. Focalizar as políticas de financiamento aparece, em todos os estudos sobre o acesso ao ensino superior, como passo essencial para o entendimento dos possíveis avanços na oferta de maior igualdade de oportunidades educacionais.

\subsection{Políticas de financiamento ou permanência: ProUni e Reuni}

A efetividade das políticas de acesso pode ser avaliada pelas suas consequências em termos de garantia da permanência de todos os estudantes até a conclusáo dos cursos escolhidos. Ainda que existam fortes indicaçóes de que os fatores culturais sejam mais relevantes para definir o acesso e a permanência no ensino superior, não há dúvidas sobre o impacto do fator econômico.

Os níveis de permanência dos alunos no SES brasileiro são muito baixos. Há dificuldades imensas no cálculo das taxas de conclusão, devido à variedade de trajetórias individuais, tanto nos ritmos de avanço nos cursos quanto na própria duração desses mesmos cursos. Usando dados fornecidos na Sinopse da Educação Superior em 2013, constata-se que houve um total de 6.152.405 matrículas nesse ano em todo o país. Desse total, apenas 491.738 estudantes concluíram os cursos em 2013. Obviamente, isso não significa que menos de $10 \%$ dos alunos que iniciam concluem os seus cursos. Mesmo assim, são muito poucos os concluintes para um investimento - público e das famílias - táo colossal. Nesse quadro, analisar as políticas voltadas para o financiamento e para a permanência dos estudantes torna-se essencial.

O Programa de Apoio a Planos de Reestruturação e Expansão das Universidades Federais (Reuni) combina perfeitamente as duas dimensóes analisadas nesse item: é uma política de financiamento e de favorecimento da permanência dos estudantes. Conforme explica Gouveia (2009, p. 34-35):

O Reuni foi lançado pelo Governo Federal através do Decreto n 6.096, em 24 de abril de 2007, e tem como objetivo criar condições para a ampliação do acesso e permanência na 
educação superior, no nível de graduação, pelo aproveitamento da estrutura física e de recursos humanos existentes nas universidades federais. [...] este projeto apresentou dois objetivos: o primeiro estaria relacionado com a elevação gradual da taxa de conclusão média dos cursos de graduação presenciais para noventa por cento - 90\% - além do aumento da relação de alunos de graduação em cursos presenciais por professor I para 18.

O Reuni financiaria obras de infraestrutura e custeio, inclusive com contratação de pessoal. A adesão ao programa pelas universidades federais foi voluntária e dependia da elaboraçáo de planos com propostas para cada instituição. Uma exigência em comum foi o aumento de pelo menos $20 \%$ da matrícula prevista anteriormente para cada universidade. Idealmente, teríamos uma universidade pública fortemente inclusiva e de boa qualidade, segundo as diretrizes do decreto de criação do Reuni.

As diretrizes, por sua vez, estariam focadas basicamente na redução das taxas de evasão, através da ocupação das vagas ociosas e no aumento no número de vagas de ingresso, especialmente no período noturno. Na ampliação da mobilidade estudantil, com a implantação de regimes curriculares e sistemas de títulos que possibilitariam a construção dos denominados itinerários informativos, mediante o aproveitamento de créditos e a circulação de estudantes entre as instituições, cursos e programas de educação superior. Na diversificação das modalidades de graduação, preferencialmente não voltadas à profissionalização precoce e especializada, assim como na ampliação de políticas de inclusão e assistência estudantil, na articulação da graduação com a pós-graduação e da educação superior com a educação básica. Estas propostas ainda contariam com a revisão da estrutura acadêmica, ou seja, a reorganização dos cursos de graduação e a atualização de metodologias de ensino-aprendizagem, a fim de uma constante elevação de qualidade das instituições federais de ensino. (GOUVEIA, 2009, p. 35-36).

Obviamente, o Decreto no 6.096/2007 traça caminhos muito importantes que podem permitir uma expressiva melhoria nas condiçóes de acesso e permanência no sistema público. Merece destaque particular a obrigatoriedade de cursos noturnos: as universidades públicas, como mostra o Censo da Educação Superior ${ }^{7}$ em 2013 (ou seja, mesmo depois do REUNI) tinham $70 \%$ de suas matrículas em cursos diurnos ao passo que as instituiçóes privadas têm $73 \%$ de seus alunos matriculados em cursos noturnos. Não é necessário

7 Todos os Censos da Educação Superior estão disponiveis no site http://portal.inep.gov.br/web/censo-da-educacao-superior. Os dados especificamente mencionados nesse ponto foram retirados da apresentação dos técnicos do INEP, disponivel no site https://www.ufmg.br/dai/textos/coletiva_censo_superior_20/3.pdf. 
insistir na relevância dos horários de funcionamento dos cursos: esse é um elemento visto como item essencial para a permanência de estudantes que trabalham há muitos anos (PAUL; VALLE SILVA, 1998; BRAGA; PEIXOTO; BOGUTCHI, 2001; ZAGO, 2006). Ou seja, sabidamente os horários de funcionamento dos cursos têm um efeito de seleção social. E, nesse sentido, essa obrigatoriedade de introdução ou reforço dos cursos noturnos nas instituiçóes públicas seria um passo - infelizmente ainda tímido, pelos dados de 2013 - para dar maior abertura a estudantes náo provenientes da elite nas universidades federais.

Há inúmeros estudos sobre o Reuni em instituições específicas. Entretanto, é muito difícil encontrar estudos sintéticos que façam uma avaliação geral do impacto dessa política. Os diversos estudos de caso disponíveis indicam alguns avanços, ligados principalmente à criação de novos cursos e à contratação de mais professores. Mas também há indicações, ainda de caráter muito impressionista e que mereceriam análises mais aprofundadas, dos problemas e dificuldades para transformar o Reuni em uma política de democratização do ensino superior. Teria havido uma expansão significativa de vagas em cursos pouco valorizados - e, talvez, não muito necessários da perspectiva da oferta de empregos. Haveria resistências fortes dos professores às licenciaturas, majoritariamente noturnas, e vistas como "cursos para pobres". Esses mesmos professores veriam esses cursos novos como a transformação da universidade em grandes colégios, em instituiçóes vocacionais, enfim, em universidades de "segunda linha" ou como sendo a segunda linha em uma universidade "de primeira"

Os números absolutos de matrícula e a distribuição por categoria administrativa dos estudantes do SES pareceria indicar que haveria (uma hipótese que possivelmente seja plausível) maiores possibilidades de democratizaçáo via setor privado (SAMPAIO, 2014; MOREIRA, 2014; ALMEIDA NETO, 2015). Seja pelo tamanho do alunado, seja pela proporção de cursos noturnos, ou, ainda, por alguma outra característica do setor privado de ensino

8 De um ponto de vista mais analítico e menos impressionista o artigo de Prates e Barbosa (2015) indica alguns elementos que permitem compreender os processos em foco. Entre esses elementos, destaca-se a força do viés acadêmico, que reforçaria os bacharelados, as teorias e perspectivas abstratas em detrimento dos diplomas de licenciatura e tecnológicos, dos conhecimentos práticos ou aplicados. 
superior, pode-se legitimamente aventar essa hipótese. Certamente, não é possível ignorar um problema crônico relativo à qualidade desse setor; mas, também, pode-se argumentar que a falta de qualidade não é uma exclusividade do sistema privado.

Sendo assim, políticas como o ProUni (Programa Universidade para Todos) merecem atençáo especial. O ProUni foi criado em 2005 tendo como finalidade a concessão de bolsas de estudos para estudantes de baixa renda em cursos de graduação e sequenciais em instituiçóes de ensino superior privadas. Foram estabelecidos vários critérios, tanto de desempenho quanto de renda, além da exigência de ter estudado o ensino médio em escola pública. São reservadas vagas também para pessoas com deficiência, pretos, pardos e indígenas. Segundo Santos (2014), mesmo tendo atendido mais de um milháo de estudantes entre 2005 e 2012, haveria, ainda, muitas questóes a serem respondidas sobre possíveis impactos democratizantes dessa política. É importante indicar que o financiamento concedido através do ProUni gera intensos debates bastante marcados ideologicamente, particularmente na comunidade autodenominada de educadores (título que talvez indique uma renúncia ao caráter profissional do trabalho docente: afinal, qualquer pai ou mãe educa, colegas educam, a vida educa). E esse debate náo é objeto deste trabalho. $\mathrm{O}$ ProUni é analisado aqui como uma política que talvez possa abrir maiores oportunidades de acesso e permanência no ensino superior para indivíduos provenientes de grupos sociais não privilegiados.

O estudo de Santos (2014) trata principalmente dos estudantes do ProUni na PUC-Rio e a dimensão institucional dessa pesquisa será retomada no próximo item. Todavia, na conclusão, a autora focaliza um fenômeno essencial (e raramente tratado na literatura brasileira sobre educação) para um estudo sobre as relações entre "Destinos e Escolhas":

Por fim, diante da constatação da importância do capital de informações para a escolha da PUC-Rio, cabe questionar se o ensino superior não continua permeado por uma lógica excludente segundo a qual apenas aqueles que estabelecem certas redes de relações têm a possibilidade de identificar a qualidade diante da heterogeneidade do sistema de ensino superior brasileiro e nortear suas escolhas com base neste conhecimento. Como a informação sobre a qualidade dos cursos e estabelecimentos não chega a todos, aqueles que conseguem estabelecer certas redes de relações têm maiores chances de perceber a hierarquia de prestígio existente entre as instituições e identificar os melhores caminhos para aproveitar 
as oportunidades disponíveis. Se os estudantes fazem suas escolhas no "escuro" e apenas alguns têm a chance de "reconhecer" e optar pela qualidade, significa abrir reais oportunidades apenas para parcela do público-alvo. (SANTOS, 20I4, p. 369).

Em sua dissertação, Santos (2011) já mostrava alguns traços das estratégias desenvolvidas pelos estudantes que entravam em instituições mais fracas e iam mudando até conseguir universidades de elite, como é o caso da PUC-Rio. Assim, fica claro que o acesso à informaçáo sobre o sistema de ensino e suas hierarquias é essencial para permitir Escolhas que efetivamente aproveitem as melhores oportunidades. Alves (2007) já mostrara como o acesso a informaçóes sobre o mercado de trabalho para sociólogos era bastante diferenciado entre os alunos da UFRJ. Entre os estudantes entrevistados naquele período que tinham origem social mais elevada, todos sabiam sobre alternativas de profissionalizaçáo fora do circuito puramente acadêmico. Do outro lado, estudantes de origem mais modesta viam na carreira acadêmica sua única alternativa de profissionalização, pois não conheciam outros tipos de empregos ou outras atividades que pudessem procurar. E, infelizmente, o curso não oferecia essas informaçôes. É bom ressaltar, também, que ainda não havia os cursos de licenciatura.

Certamente esse foco nas políticas de financiamento é muito particular e incompleto. No entanto, a menção dessas políticas permite tratar de dimensóes propriamente institucionais do processo de geração de oportunidades educacionais.

\subsection{Ações institucionais para permanência de estudantes no SES}

A multiplicação de estudos sobre as estratégias institucionais para garantir a permanência dos seus alunos pode ser vista como mais um indicador da importância que a educação superior vem ganhando na agenda pública. A força da sociologia durkheimiana cresce muito nesses estudos que utilizam conceitos e métodos do mestre fundador da nossa ciência. A integração moral e o fortalecimento da coesão social produzidas por atividades coletivas nas instituiçóes são bases essenciais para garantir a permanência dos indivíduos na universidade (GOUVEIA, 2009; HERINGER; HONORATO, 2014). Esse tipo de abordagem é fortalecido por trabalhos como os de Vincent Tinto (1997) que dá peso ao argumento de que as experiências vividas pelos estudantes dentro das instituiçóes têm impactos relevantes na permanência na 
universidade, destacando que o ambiente universitário e as interaçóes com outros estudantes resultariam em impactos sobre a maior ou menor integração (que conduziria a maior ou menor permanência) dos estudantes na instituição. A sociologia de Durkheim sobre o suicídio oferece, também, as bases metodológicas para o uso da chamada "[...] análise de sobrevivência (Survival Analysis), especificamente o método de regressão de Cox, no estudo do fluxo escolar a partir da construção de bancos de dados longitudinais" (ALMEIDA NETO, 2015, p. 29).

Nesse ponto, entramos mais claramente na análise das formas pelas quais os processos institucionais podem representar o apoio necessário para viabilizar o sucesso das trajetórias escolares de jovens menos privilegiados financeiramente. Entretanto, algumas políticas desenvolvidas em instituiçóes federais tem tido um alcance muito limitado.

De qualquer forma, o "processo de afiliação" ou de "integração moral” guardaria especificidades de acordo com aspectos institucionais, incluindo recursos e arranjos que imputariam limites ou não a ele/s, além das características da origem social familiar e de outros grupos dos quais os alunos fazem parte. As políticas de assistência estudantil poderiam, nesse quadro teórico, facilitar a afiliação ou integração dos estudantes, mas elas parecem ainda estar engatinhando no Brasil. (HERINGER; HONORATO, 20I4, p. 323).

Retomando o estudo de Santos (2014, p. 368) sobre o ProUni na PUC-Rio, encontramos mais uma indicação de que as instituições públicas de ensino superior enfrentam dificuldades em objetivar modelos de funcionamento que contribuam para a permanência dos estudantes das camadas populares.

Os resultados da pesquisa apontam que o apoio, material e emocional, oferecido pelas famílias bem como a existência de uma estrutura de auxílios aos estudantes pobres, anterior à implantação do ProUni na PUC-Rio, se mostraram fundamentais para garantir a permanência dos bolsistas participantes do Programa. Na ausência de iniciativas governamentais de maior abrangência voltadas para a permanência, são estes os dois atores que têm proporcionado a superação dos desafios advindos com a vida universitária.

Reaparecem as indicaçóes anteriores (ALMEIDA, 2009; PRATES, 2007; PRATES; FALEIROS, 2014) de que as universidades públicas não sabem muito bem como lidar com seus novos alunos. Por outro lado, considerar as universidades católicas como instituiçóes privadas também náo é simples. Entretanto, em termos de integraçáo dos estudantes ao projeto universitário 
as PUCs parecem bem mais avançadas que instituiçóes públicas, particularmente as federais aqui estudadas.

Outra política institucional extremamente importante - e no caso em pauta, realizada por uma universidade federal - é a interiorização. Proposta do REUNI, a interiorização visaria a garantir ensino público de qualidade para as populaçóes no interior dos estados e também reduzir as desigualdades regionais de oferta de ensino superior. Como outras iniciativas visando à expansão do SES, a interiorização sofreu críticas de quase todos as posiçóes políticas no campo da educação tornando mais difícil e mais complexa a implantação dessa que poderia ser considerada uma inovação em nosso país (VARGAS, 2014). Aliás, esse é um debate ainda a ser feito no Brasil. Nosso país, de dimensóes continentais, manteve-se durante séculos agarrado à costa e deixando um vasto mundo de fora do desenvolvimento e da modernidade que, mesmo incompletos, apareciam por aqui. Uma economia pujante, uma agroindústria de primeiro mundo, e outros tantos fatos novos deixam o SES um tanto atrasado no processo. Principalmente no setor público, pois as instituiçóes privadas invadiram, literalmente, o interior do país.

Muitas vezes a excelência é usada como argumento para dificultar a interiorização (VARGAS, 2014, p. 391) ou mesmo contra a implantação de cursos ministrados a distância, náo presenciais (PREDES et al., 2014). Entretanto, pouco se avança em termos da regulaçáo da qualidade no país e as autoridades da área muitas vezes parecem perdidas sobre como controlar e exigir a excelência, principalmente no setor privado (CASTRO, 2014, p. 71-72). Logo, a discussão tem andado bastante no plano abstrato, mas as realizaçóes concretas - como avaliação da educaçáo a distância, dos efeitos da educação superior em todas as modalidades no mercado de trabalho, da eficiência científica da nossa produção - ainda deixam muito a desejar. Apenas começam a ser feitas. Mas o estudo de Vargas (2014, p. 309) já indica que a qualidade dos cursos não pareceu sofrer com a interiorização:

A comparação entre o desempenho discente em Niterói e no interior, para os mesmos cursos, revela que os resultados se igualam em dois casos: Direito e Odontologia. Mas o interior supera Niterói em seis cursos: Administração, Ciência da Computação, Engenharia de Produção, Pedagogia, Psicologia e Serviço Social. No caso de Pedagogia, Psicologia e Serviço Social, a superioridade do interior pode dever-se ao boicote ao exame, realizado por esses cursos em Niterói. O interior perde para Niterói nos cursos de Engenharia Mecânica, Matemática e Turismo. 
Como outras políticas de interiorização, aquela da UFF enfrentou forte resistência dos alunos - que chegaram a ocupar a reitoria dessa universidade, alegando que o Reuni não oferecia as condiçóes por eles demandadas (mas náo explicitadas) para uma educaçáa pública de qualidade. Foi preciso recorrer ao judiciário para implantar o programa de interiorizaçáo, parte do Reuni. Mesmo antes do Reuni a UFF já é, há muitos anos, a universidade mais interiorizada do estado do Rio, estando presente em 16 municípios. O foco da análise de Vargas no público que, em cada município, estava disposto ou tinha possibilidades de entrar para a universidade introduz uma questão essencial do planejamento: como o (suposto) público-alvo lida com a oferta institucional.

Obviamente, políticas de interiorizaçáo necessitam de longos prazos para darem seus frutos. O que parecia um delírio de Zeferino Vaz - fundador da Unicamp - no começo dos anos 1960 produziu uma das melhores universidades do país. A Universidade Federal de São Carlos é outro sucesso da interiorização. Então, possivelmente os problemas apontados nesta análise sejam resultantes do caráter ainda muito inicial - em termos de tempo histórico - desse processo. Mas os dados da avaliação mostrados indicam que a instituiçáo ainda tem muito a investir nos modos de funcionamento dos cursos no interior, na relação com os estudantes e, talvez, na própria escolha dos cursos oferecidos e dos métodos de informação e (tomara!) de formação.

Talvez essa baixa concorrência convirja para explicar o fato de que a UFF apresentou em 201 I a maior oferta de vagas entre as maiores federais (UFRJ, UNB, UFMG e UFPA), conforme mencionado, mas seja a segunda em ingressos nesse mesmo ano, ficando abaixo da UFRJ. Já em relação à taxa de conclusão, a UFF fica em último lugar dentre aquelas federais em todos os anos desde 2007. Neste caso, algumas hipóteses devem ser aventadas: [...] uma inadequação entre locais de oferta e cursos ofertados; [...] os problemas relacionados a carência de pessoal, ausência ou precária representação política, péssima estrutura física de trabalho, condições de trabalho e carreira fragilizadas. [...]. Sem dúvida, más condições de trabalho e de estudo não apenas desmotivam a permanência dos alunos quanto dissuadem futuros candidatos. As notícias e avaliações circulam [...]. (VARGAS, 2014, p. 303).

Seria muito interessante analisar a resistência do corpo docente a essa política que, teoricamente, expandiu o número de oportunidades para que pessoas residentes no interior do estado tivessem acesso a uma universidade pública e gratuita. Na prática, certamente, foi bastante estendido o número 
de vagas para professores. Uma questáo importante - não mencionada neste estudo - diz respeito ao local de residência desses novos professores. Os docentes contratados para as unidades do interior residem onde? A discussáo sobre uma possível precarização do trabalho docente passaria necessariamente por esse ponto.

Um pouco mais otimista que os estudos anteriormente mencionados sobre as universidades públicas, o caso da UFF parece oferecer indicaçóes de que essas instituiçóes podem, sim, oferecer maiores oportunidades educacionais, efetivas e de qualidade. Ajustes são necessários: por parte da universidade, possivelmente melhorar os sistemas de informação sobre e para o público. Por parte dos movimentos sociais de docentes, discentes e funcionários, talvez, uma compreensão mais adequada do sentido social do processo de expansão do ensino superior via interiorização, ou seja, ampliar as possibilidades de Escolha para as pessoas que tiveram o Destino de nascer ou viver no interior do país.

Outro fator institucional que merece ser focalizado nesse artigo é o que Almeida Neto batizou de "configuração escolar" na sua tese sobre os estudantes de ciências sociais na PUC-Minas, em Belo Horizonte. Considerando o quadro de desigualdades no Brasil e o peso da origem social sobre o destino ocupacional em nosso país, o estudo busca identificar

[...]. as chances de sucesso (ou "sobrevivência") de estudantes - em sua maioria, com pais de média e baixa escolaridade e provenientes de estratos socioeconômicos médios/baixos - no ensino superior a partir de uma determinada "configuração escolar", que oferece um conjunto de oportunidades que permite a uma parcela deles se integrar e se dedicar exclusivamente ao curso. (ALMEIDA NETO, 2015, p. 23).

Nessa tese, são identificadas formas de atuação institucional que atuam como proteção dos estudantes contra as determinaçóes de sua origem social. Uma característica marcante da história da PUC-Minas foi sua preocupação com o desenvolvimento de políticas de estágios, bolsas e diversas formas preparatórias para futura inserção profissional (SOLIVELLAS PERELÓ, 1998). O trabalho agora em pauta indica a persistência dessas políticas e, num certo sentido, seu sucesso. Utilizando uma combinaçáo refinada de métodos quantitativos e qualitativos, o trabalho de Almeida Neto (2015, p. 166, grifo nosso) demonstra, como o próprio autor admite, que a universidade pode anular os efeitos da origem e da trajetória social anterior: 
Os resultados do estudo demonstraram que as variáveis socioeconômicas, como renda familiar, escolaridade dos pais e tipo de escola cursada nos ensinos fundamental e médio, não tiveram impacto sobre o fluxo escolar [...] os resultados da pesquisa parecem evidenciar que o que mais influenciou positivamente as chances de sucesso no ensino superior e, posteriormente, no campo profissional não foi a origem social dos alunos, mas a oferta de condições de permanência e dedicação ao curso e de fruição do ambiente universitário através de atividades remuneradas de pesquisa, estágio e extensão.

Esse talvez seja o ponto mais relevante do argumento aqui desenvolvido: a reafirmação de que, mesmo em condições adversas, tais como a origem social modesta dos alunos e a entrada em um curso pouco valorizado socialmente, as condiçóes oferecidas pela instituição podem redefinir as probabilidades de sucesso escolar. Existiria efetivamente um efeito da instituição universitária. Os chamados alunos não tradicionais (baixa renda, mais velhos, pertencentes a minorias étnicas, provenientes do interior) foram exatamente os que mais persistiram no curso e que conseguiram inserção no mercado mais próxima da sua formação. Claro, isso acontece com aqueles que participaram ativamente das atividades oferecidas pela instituiçáo. Nesse sentido, sua experiência escolar (no sentido de Dubet) teve impacto mais significativo que a própria origem social. Em outros termos, a ação institucional gerou condições para que a Escolha desses jovens prevalecesse sobre o seu Destino social.

\section{Possíveis avanços da pesquisa}

Como diz Dubet (2015) no texto que orientou boa parte dos argumentos aqui desenvolvidos, a expansão e até mesmo massificação (que certamente ainda não ocorre no caso brasileiro) do SES não indica necessariamente uma democratização. Mesmo quando se verifica que alguns grupos antes excluídos claramente se beneficiaram dessa expansão. É o caso das mulheres, que entraram maciçamente na universidade a partir da reforma Passarinho, ou dos negros, que aumentaram sua participação no ensino superior em anos mais recentes. O recente estudo de Martins e Machado (2015) mostra que o percentual de negros entre as pessoas com ensino superior completo passou de 14,83\% em 2000 para 25,46\% em 2010. Já as mulheres foram de 56,98\% para $60,90 \%$ no mesmo período.

Certamente, esses são indícios de abertura importante do acesso ao ensino superior no Brasil. No entanto, há alguns anos, a pesquisa em sociologia 
da educaçáo vem mostrando que o aumento da igualdade de oportunidades educacionais tem resultado em taxas de sucesso. E, além da família, o recurso social relevante para definir essas taxas de sucesso é o funcionamento da instituição escolar.

Na primeira parte, foram analisados alguns elementos do SES que tenderiam a indicar a persistência e durabilidade das desigualdades sociais. Inúmeros estudos feitos no Brasil e em diversos países mostrariam uma tendência ao recrudescimento da desigualdade mesmo em contextos de forte expansão da matrícula e do contingente populacional que passou pelo ensino superior. No entanto, outras pesquisas indicariam que a manutenção, o reforço ou a diminuição dessas estruturas de desigualdade passam por valores, práticas institucionais, açóes coletivas. Essas práticas e valores podem aumentar ou diminuir as desigualdades, especialmente aquelas no topo do sistema educacional.

A partir dessa perspectiva menos determinística, buscou-se construir evidências favoráveis a um trabalho de construção institucional que tivesse - probabilisticamente - efeitos democratizantes sobre o sistema de ensino superior. As evidências são tênues e, pelo menos em alguns casos, permitem leituras diferentes. Entretanto, tanto as políticas governamentais quanto as açôes institucionais contêm indicaçôes de algum sucesso. A interiorização da UFF combina princípios de uma política federal com uma açáo institucional e tem resultados positivos em matéria de qualidade dos cursos instalados no interior. A PUC-Minas faz políticas de estágios e de acolhimento institucional que resultam em boas taxas de conclusão e de entrada qualificada no mercado de trabalho. O Reuni aumentou efetivamente as vagas em instituiçóes públicas e o ProUni ainda abre espaços importantes para realização de cursos em universidades privadas, algumas de excelente qualidade.

Nesse sentido, é possível confirmar a existência de açôes e políticas que criam probabilidades efetivas de que Escolhas dos indivíduos e grupos possam prevalecer sobre os Destinos socialmente desenhados para eles. Claro que isso ocorre com dificuldades imensas. Tilly (1998) já indicara que as desigualdades culturais e sociais são mais duráveis, persistentes e difíceis de ser combatidas. Mas talvez seja possível pensar mecanismos de reconstrução da solidariedade social que façam com que a sociedade prefira a igualdade. Segundo Dubet (2014, p. 3), o recrudescimento da desigualdade seria proveniente do esfacelamento dos laços sociais que nos fariam desejar a igualdade de todos. Nossas 
práticas e nossas representaçóes, nossos atos e nossos valores produzem desigualdade da mesma forma que as relaçóes econômicas. Para que o sistema de ensino superior no nosso país deixe de ser o Destino exclusivo da elite para se tornar uma Escolha possível para qualquer cidadão, seria importante rever nossas representaçóes e práticas do que deva ser esse sistema e o seu funcionamento. Um sistema de ensino superior mais justo e aberto, mais inclusivo e mais coesivo.

\section{Referências}

ALMEIDA, W. M. Estudantes com desvantagens econômicas e educacionais e fruição da universidade. Caderno CRH, Salvador, v. 20, n. 49, p. 35-46, 2007.

USP para todos? Estudantes com desvantagens socioeconômicas e educacionais e fruição da universidade pública. São Paulo: Musa, Fapesp, 2009.

ALMEIDA NETO, Manuel. Novos atores no Ensino Superior Brasileiro: Impactos do perfil socioeconômico e das condições pós-acesso sobre o fluxo escolar e inserção profissional de estudantes de Ciências Sociais de uma instituição privada. 2015. 122 f. Tese (Doutorado em Sociologia) - Programa da Pós-Graduação em Sociologia, Universidade federal de Minas Gerais, Belo Horizonte, 2015.

ALVES, A. P. G. Objetivaçáo participante: um estudo sobre a identidade profissional dos sociólogos da cidade do Rio de Janeiro. 2007. 153 f. Dissertação (Mestrado em Sociologia e Antropologia) - Programa de Pós-graduação em Sociologia e Antropologia, Universidade Federal do Rio de Janeiro, Rio de Janeiro, 2007.

BAKER, D. P. The Schooled Society: The educational transformation of global culture. Stanford, California: Stanford University Press, 2014.

BARBOSA, M. L. O. Training in architecture: how professionals are produced. In: LARA, F.; MARQUES, S. (Ed.). Architectural education? Quidi novi? , Austin, Texas, nhamerica, 2015 , p. $56-80$

.; SANTOS, C. T. A permeabilidade social das carreiras do ensino superior. Cadernos do CRH [Online], Salvador, v. 24, n. 63, p. 535-554, set./dez. 2011. Disponível em: <http:// www.scielo.br/pdf/ccrh/v24n63/06.pdf>. Acesso em: 9 set. 2015.

.; ZUCCARELLI, C. A formação nas áreas de CTEM: saberes modernos em instituições tradicionais In: In: OLIVEIRA, M. P. P. (Org.). Formação de Profissionais das 
áreas de Ciência, Tecnologia, Engenharia e Matemática (CTEM). 1. ed. Brasília: ABDI/IPEA, 2014. v. IV. p. 63-98.

BASTOS, A. P. B. L. Herdeiros ou sobreviventes: mobilidade social no ensino superior. 2004. 167 f. Dissertação (Mestrado em Sociologia e Antropologia) - Programa de Pós-graduaçáo em Sociologia e Antropologia, Universidade Federal do Rio de Janeiro, Rio de Janeiro, 2004.

BOLIVER, V. Maximally Maintained Inequality and Effectively Maintained Inequality in Education: Operationalizing the Expansion-Inequality Relationship. Sociology Working Papers, Paper n. 2010-05, Department of Sociology, University of Oxford. 2010. Disponível em: <http://www.sociology.ox.ac.uk/materials/papers/2010-05.pdf >. Acesso em: 9 set. 2015.

BRAGA, M. M.; PEIXOTO, M. C.; BOGUTCHI, T. Tendências da demanda pelo ensino superior: Estudo de caso da UFMG. Cadernos de Pesquisa - Fundação Carlos Chagas, São Paulo, n. 113, p. 129-152, 2001.

CARRANO, P. C. R. Jovens Universitários: acesso, formação, experiências e inserção profissional. In: SPÓSITO, M. P. (Ed.). O Estado da Arte sobre juventude na pós-graduação brasileira: Educação, Ciências Sociais e Serviço Social (1999-2006). 1. ed. Belo Horizonte: Argumentum, 2009. v. 1. p. 179-228.

CARUSO, L. Identificação de mudanças em profissóes de nível superior em um cenário prospectivo otimista. In: BARBOSA, M. L. (Org.). Ensino Superior: Expansão e Democratização. Rio de Janeiro: Editora 7 Letras, 2014. p. 259-272.

CASTRO, M. H. M. Universidade: a quantas anda nossa excelência e relevância? In: BARBOSA, M. L. (Org.). Ensino Superior: Expansão e Democratização. Rio de Janeiro: Editora 7 Letras, 2014. p. 71-102.

DUBET, F. La préférence pour l'inégalité: comprendre la crise des solidarités. Paris: Seuil, 2014.

Qual a democratizaçáo do ensino superior. Caderno CRH, Salvador, v. 28, n. 74, p. 255-265, maio/ago. 2015. Disponível em: <http://www.scielo.br/pdf/ccrh/v28n74/01034979-ccrh-28-74-0255.pdf>. Acesso em: 9 set. 2015.

FORQUIN, J. C. Sociologia da Educação: dez anos de pesquisa. Petrópolis: Vozes, 1995.

GOLDTHORPE, J. Problems of 'Meritocracy'. In: HALSEY, H. A. et al (Org.) Education: Culture, Economy, Society. Oxford: Oxford University Press, 1997. p. 688-702 
GOLDTHORPE, J.; JACKSON, M. Education Based Meritocracy: The Barriers to its Realization. In: LAREAU, A.; CONLEY, D. (Ed.) Social class: how does it work? New York: Russell Sage Foundation, 2008, p. 93-116.

GOUVEIA, A. P. Acesso e permanência nos cursos de graduação da UFRJ: o Centro de Filosofia e Ciências Humanas. 2004. 202 f. Dissertação (Mestrado em Antropologia) Programa de Pós-Graduação em Sociologia e Antropologia, Universidade Federal do Rio de Janeiro, Rio de Janeiro, 2004.

GRIPP, G. Políticas educacionais e as políticas de currículo do ensino superior. In: BARBOSA, M. L. (Org.). Ensino Superior: Expansão e Democratização. Rio de Janeiro: Editora 7 Letras, 2014. p. 177-214.

HERINGER, R.HONORATO, G: Políticas de permanência e assistência no ensino superior público e o caso da Universidade Federal do Rio de Janeiro (UFRJ) In: BARBOSA, M. L. (Org.). Ensino Superior: Expansão e Democratização. Rio de Janeiro: Editora 7 Letras, 2014, p 264-296

JENCKS, C. et al. Inequality: A Reassessment of family and Schooling in America, New York, Basic Books, 1972.

MAINARDES, J.; GANDIN, L. A. Contributions of Stephen J. Ball to the research on educational and curriculum policies in Brazil. London Review of Education, v. 11, n. 3, p. 256-264, 2013.

MARTINS, Carlos Benedito NOTAS SOBRE A FORMAÇÃO DE UM SISTEMA

TRANSNACIONAL DE ENSINO SUPERIOR Caderno CRH, Salvador, v. 28, n. 74, p. 291-308, maio/ago. 2015. Disponível em: <http://www.scielo.br/pdf/ccrh/v28n74/01034979-ccrh-28-74-0255.pdf>. Acesso em: 9 set. 2015.

MARTINS, F. dos; MACHADO, D. C. Determinantes do acesso ao ensino superior no Brasil e a probabilidade de sucesso por curso. Economia - Texto para discussão 317, Rio de Janeiro, p. 1-26, 2015. Disponível em: http://www.proac.uff.br/econ/sites/default/files/uff_td317. pdf>. Acesso em: 9 set. 2015.

MOEHLECKE, S. Açáo afirmativa: história e debates no Brasil. Cadernos de Pesquisa, n. 117, p. 197-217, nov. 2002. Disponível em: <http://www.scielo.br/pdf/cp/n117/15559.pdf>. Acesso em: 9 set. 2015.

MOREIRA, A. M. A. Público e privado no ensino superior: uma análise comparativa por características institucionais. In: BARBOSA, M. L. (Org.). Ensino Superior: Expansão e Democratização. Rio de Janeiro: Editora 7 Letras, 2014. p. 155-176. 
NEVES, C. E. B.; ANHAIA, B. Políticas de Inclusão Social no Ensino Superior no Brasil: políticas de redistribuição de oportunidades? Reflexôes a partir das experiências em IES do Rio Grande do Sul. In: BARBOSA, M. L. (Org.). Ensino Superior: Expansão e Democratizaçáo. Rio de Janeiro: Editora 7 Letras, 2014. p. 371-402.

OLIVEIRA, M. P. P de O. et al. em 2014. Rede de pesquisa: formação e mercado de trabalho: coletânea de artigos: volume IV, formação de profissionais das áreas de Ciência, Tecnologia, Engenharia e Matemática (CTEM). Brasília: ABDI: IPEA, 2014. v. 4. Disponível em: <http:// www.abdi.com.br/Estudo/141027_abdi_ipea_vol4.pdf. Acesso em: 9 set. 2015.

PAUL, J. J.; VALLE-SILVA, N. do. Conhecendo o seu lugar: a auto-seleção na escolha da Carreira. Revista Brasileira de Política e Administração da Educação, Brasília, n. 14, v. 14, p. 115-130, 1998.

PRATES, A. A. P. Universidades VS Terceirização do Ensino Superior: a lógica da expansão do acesso com manutençáo da desigualdade. O caso brasileiro. Sociologias, ano 9, n. 17, p. 102-123, jan./jun. 2007.

.; BARBOSA, M. L. A expansão e as possibilidades de democratização do ensino superior no Brasil. Caderno CRH [Online], v. 28, p. 327-340, 2015.

; FALEIRO, M. S. Os efeitos Diferenciais do tipo de instituição de Ensino Superior sobre o Prestígio dos seus Egressos no Mercado de Trabalho. In: BARBOSA, M. L. (Org.). Ensino Superior: Expansão e Democratização. Rio de Janeiro: Editora 7 Letras, 2014. p. 129-154.

PREDES, R. et al: A nova expansão de cursos de graduação - presenciais e a distância - em Serviço Social no Brasil e em Alagoas no contexto da Política de Ensino Superior do Governo Federal no período 2003 a 2010. In: BARBOSA, M. L. (Org.). Ensino Superior: Expansão e Democratização. Rio de Janeiro: Editora 7 Letras, 2014. p. 273-286.

RIBEIRO, C. A. C.; CENEVIVA, R.; BRITO, M. Estratificação educacional entre jovens no Brasil:1960 a 2010. In: ARRETCHE, M. (Org.). Trajetórias das desigualdades: como o Brasil mudou nos últimos 50 anos. São Paulo: Ed. Unesp/CEM, 2015. p. 335-364.

SAMPAIO, H. O setor privado de ensino superior no Brasil: crescimento, mercado e Estado entre dois séculos. In: BARBOSA, M. L. (Org.). Ensino Superior: Expansão e Democratização. Rio de Janeiro: Editora 7 Letras, 2014. p. 103-126.

SANTOS, C. T. A chegada ao ensino superior: o caso dos bolsistas do ProUni da PUCRio. 2011. 176 f. Dissertação (Mestrado em Sociologia e Antropologia) - Programa de 
Pós-graduação em Sociologia e Antropologia, Universidade Federal do Rio de Janeiro, Rio de Janeiro, 2007.

A chegada ao ensino superior: o ProUni na PUC-Rio. In: BARBOSA, M. L. (Org.).

Ensino Superior: Expansão e Democratização. Rio de Janeiro: Editora 7 Letras, 2014. p. 351-370.

SCHOFER, E.; MEYER, J. The Worldwide Expansion of Higher Education in the Twentieth Century, American Sociological Review, v. 70, n. 6, p. 898-920, dec. 2005.

SCHWARTZMAN, S. A universidade primeira do Brasil: entre intelligentsia, padrão internacional e inclusão social. Estud. av. [online], São Paulo, v. 20, n. 56, p. 161-189, jan./ abr. 2006. Disponível em: <http://www.scielo.br/scielo.php?script=sci_arttext\&pid=S0103$40142006000100012 \& \operatorname{lng}=$ en\&nrm=iso $>$. Acesso em: 9 set. 2015.

Solivellas Pereló, J: Pedagogia do Estágio: Experiências de formação, Belo Horizonte, PUCMG, 1998.

TILLY, C. Durable Inequality. Berkeley: University of California Press, 1998.

TINTO, V. Classrooms as Communities: exploring the educational character of student persistence. The Journal of Higher Education, v. 68, n. 6, p. 599-623, 1997.

VARGAS, H. O Reuni na Universidade Federal Fluminense: aspectos da interiorização. In: BARBOSA, M. L. (Org.). Ensino Superior: Expansão e Democratização. Rio de Janeiro: Editora 7 Letras, 2014. p. 289-314.

ZAGO, N. Do acesso à permanência no ensino superior: percursos de estudantes universitários de camadas populares Revista Brasileira de Educaçáo, v. 11 n. 32, p. 226-237, maio/ago. 2006. 


\section{Destinations, choices and the democratization of Higher Education}

\section{Abstract}

This article analyzes some of the various policies (both governmental and institutional) aimed at ensuring the access and retention of students until the completion of the courses in the Brazilian higher education system. It is an attempt to improve the discussion about what would be a possible democratization for that system. The article seeks to determine whether, despite the maintenance of structural inequality patterns, prestige and income, you could find policies that oppose this trend. The policies examined were the racial and social quotas, the Reuni, the ProUni, and the interiorizing program of UFF and internships and scholarships at PUC-Minas. The analysis was based on the studies carried out by researchers from LAPES/UFRJ/CNPq. The analysis confirms the existence of actions and policies that create effective probabilities that individuals and groups choices prevail over destinations socially designed for them.

Keywords: Higher education. Democratization. Social policies. Access to higher education. Permanence in higher education. 